\title{
CLINICAL AND BIOCHEMICAL DETERMINANTS OF METABOLIC SYNDROME AMONG ROMA AND NON-ROMA SUBJECTS IN THE EASTERN PART OF SLOVAKIA
}

\author{
Ján Fedačko ${ }^{1}$, Daniel Pella ${ }^{1}$, Peter Jarčuška ${ }^{1}$, Leonard Siegfried ${ }^{2}$, Martin Janičko ${ }^{1}$, Eduard Veselíny ${ }^{1}$, František \\ Sabol $^{3}$, Pavol Jarčuška ${ }^{4}$,Mária Mareková5, Andrea Madarasová Gecková6, ${ }^{12}$, Peter Pažinka ${ }^{7}$, Monika Jankajová8, \\ Ján Kmec ${ }^{9}$, Marián Babčák ${ }^{9}$, Peter Kalanin ${ }^{10}$, Sylvia Dražilová ${ }^{11}$; HepaMeta Team* \\ ${ }^{11}$ st Department of Internal Medicine, P. J. Šafárik University in Košice, Faculty of Medicine and L. Pasteur University Hospital, Košice, Slovakia \\ ${ }^{2}$ Department of Medical Microbiology, P. J. Šafárik University in Košice, Faculty of Medicine and L. Pasteur University Hospital, Košice, Slovakia \\ ${ }^{3}$ Department of Cardiosurgery, Eastern Slovak Cardiovascular Institute, Košice, Slovakia \\ ${ }^{4}$ Department of Infectious Diseases, P. J. Šafárik University in Košice, Faculty of Medicine and L. Pasteur University Hospital, Košice, Slovakia \\ ${ }^{5}$ Department of Medical Biochemistry, P. J. Šafárik University in Košice, Faculty of Medicine and L. Pasteur University Hospital, Košice, Slovakia \\ ${ }^{6}$ Olomouc University Social Health Institute, Palacký University in Olomouc, Olomouc, Czech Republic \\ ${ }^{71} 1$ st Department of General Surgery, P. J. Šafárik University in Košice, Faculty of Medicine and L. Pasteur University Hospital, Košice, Slovakia \\ ${ }^{8}$ Department of Cardiology, Eastern Slovak Cardiovascular Institute, Košice, Slovakia \\ ${ }^{9}$ Department of Cardiology and General Internal Medicine, J. A. Reiman Hospital, Prešov, Slovakia \\ ${ }^{10}$ Department of Family Medicine, P. J. Šafárik University in Košice, Faculty of Medicine and L. Pasteur University Hospital, Košice, Slovakia \\ ${ }^{11}$ Department of Internal Medicine, Poprad Hospital, Poprad, Slovakia \\ ${ }^{12}$ Health Psychology Unit, Department of Public Health, Faculty of Medicine, P. J. Šafárik University in Košice, Košice, Slovakia
}

\section{SUMMARY}

Background: The metabolic syndrome (MS) is a clustering of cardiovascular risk. The high prevalence of metabolic syndrome among populations of lower socioeconomic status is a cause of concern and calls for an effective public health response.

Objectives: The aim of this study was to determine the prevalence of metabolic syndrome in the Roma population compared with the non-Roma population in the eastern part of Slovakia and to determine the parameter which has the strongest association with metabolic syndrome.

Results: 123 Roma and 79 non-Roma patients with metabolic syndrome were evaluated. In the subgroup of Roma men, we found that waist circumference conferred the highest chance of MS (more than 12-times), followed by triglycerides (TG) (3.670-times). In the subgroup of nonRoma men, we found that waist circumference conferred the highest chance of MS (more than 16-times), followed by high-density lipoprotein $(\mathrm{HDL})$ (4.348-times increased risk per one unit decrease in $\mathrm{HDL}$ ). In the subgroup of Roma women as well as non-Roma women, we found that serum TG conferred the highest chance of MS, followed by waist circumference for Roma women. Comparing non-classical risk factors for MS we found that only age (with OR 1.977) and high-sensitivity C-reactive protein (hSCRP) (OR 1.887) were significant and independent predictors of MS in Roma men. Among Roma women apolipoprotein B100 was also found to be an independent predictor of MS, besides age and hsCRP.

Conclusion: Our study confirmed that the prevalence of metabolic syndrome is strongly associated with hypertriglyceridemic waist, besides other risk factors, a marker of the atherogenic metabolic triad among younger Roma population, which may be the reason for the increased cardiovascular (CV) morbidity and mortality in elderly Roma compared with non-Roma. In light of these results, better prevention of CV events for Roma minority settlements in Slovakia should be provided.

Key words: metabolic syndrome, Roma population, laboratory biomarkers, cardiovascular risk factors, obesity

Address for correspondence: D. Pella, 1st Department of Internal Medicine, P. J. Šafárik University in Košice, Faculty of Medicine and L. Pasteur University Hospital, Tr. SNP 1, 04011 Košice, Slovakia. E-mail: daniel.pella@upjs.sk

\section{INTRODUCTION}

Regional obesity appears to be an independent contributor to cardiovascular disease at a given level of general adiposity, and its effect is only partially mediated through promotion of other

*HepaMeta Team members are listed in Appendix known risk factors. These data suggest that cardiovascular disease is as closely linked to abdominal as to general adiposity (1).

Obesity-induced metabolic syndrome is a multidimensional risk factor for cardiovascular diseases (CVD) and type 2 diabetes. Several recent reports (2-5) indicate that the presence of metabolic syndrome is associated with increased risk for both CVD and type 2 diabetes. Persons with metabolic syndrome have at least a 2-fold increased risk for CVD. Risk for type 2 diabetes in 
both men and women is increased about 5-fold (6). Relative risk for coronary heart disease (CHD) is raised 2- to 3-fold, but once CHD becomes manifest in a patient with diabetes, the prognosis for survival is greatly reduced (7). Early identification, treatment and prevention of metabolic syndrome present a major challenge for health care professionals facing an epidemic of overweight and sedentary lifestyle (5).

Ethnic minorities have been reported to have increased medical risk more frequently than majority populations (8-10). In the Slovak Republic, Roma are considered to be the second-largest minority group (11). Some findings suggest that the risk of atherogenesis in the Roma minority has considerably increased and that this is caused by unfavourable factors such as an increase in the prevalence of obesity, hypertension, smoking, and deficiency in protective substances leading to dyslipidemia, hyperinsulinemia, cardiovascular diseases, metabolic syndrome and diabetes (12).

The high prevalence of metabolic syndrome among populations of lower socioeconomic status is a cause of concern and calls for an effective public health response (13). Previous studies have confirmed higher mortality and lower life expectancy for Roma than for non-Roma (14).

The aim of this study was to determine the prevalence of metabolic syndrome in the Roma population compared with the non-Roma population in the eastern part of Slovakia and to determine the parameter which has the strongest association with metabolic syndrome.

\section{MATERIALS AND METHODS}

Data from the cross-sectional HepaMeta study conducted in Slovakia in 2011 were used. This project aimed to map the prevalence of metabolic syndrome, CV risk factors and high-sensitivity C-reactive protein (hsCRP) as one of possible novel risk factor of CV diseases in the population living in eastern Slovakia including Roma. The sample consisted of 452 Roma (mean age = 34.7; $35.2 \%$ men) and 403 non-Roma (mean age $=33.5$; $45.9 \%$ men) respondents. Roma in selected settlements were recruited by local Roma community workers. Respondents from major population were randomly selected from a list of patients from general practitioners. Data were collected via questionnaire, anthropometric measures and analyses of blood samples. Clinical biochemistry tests for determination substrates: glucose, proteins (hs-CRP as a risk factor), enzymes (gamma-glutamyl transferase - GGT) and lipid parameters (triacylglycerols - TAG or TG, total cholesterol - TC, HDL cholesterol - HDL-C, LDL cholesterol - LDL-C). All biochemical parameters were determined by routine biochemical methods on analyser ADVIA 2400 or 1650 . Excessive alcohol use was defined as an intake of over $20 \mathrm{~g}$ of alcohol a day on average, based on answers in the questionnaire, and those patients were excluded. The methodology is described in detail elsewhere (15).

\section{Statistical Analysis}

Categorical data is presented in absolute count and percentages; interval data is presented as median (interquartile range) because of nonparametric distribution. Measurement of statistical significance of difference between categorical data was performed using the chi-square test, and for interval data by the Mann-Whitney U test.

\section{RESULTS}

We screened a total of 420 Roma and 382 non-Roma participants. From these, 123 Roma and 79 non-Roma participants with metabolic syndrome were selected for further evaluation (Table 1). We found HDL cholesterol statistically lower for both Roma

Table 1. Study population with metabolic syndrome. Presented as median (IQR), BMI, smoking as percentage (n)

\begin{tabular}{|c|c|c|c|c|c|c|}
\hline & $\begin{array}{c}\text { Roma men } \\
n=47\end{array}$ & $\begin{array}{c}\text { Non-Roma men } \\
n=38\end{array}$ & $p$ & $\begin{array}{c}\text { Roma women } \\
n=76\end{array}$ & $\begin{array}{l}\text { Non-Roma women } \\
n=41\end{array}$ & $p$ \\
\hline Age & $40.4(10.8)$ & $36.7(9.5)$ & ns & $42.5(9.8)$ & $39.8(8.1)$ & ns \\
\hline Cholesterol & 4.9 (1.59) & $5.67(1.43)$ & ns & $5.09(1.26)$ & $5.6(1.63)$ & ns \\
\hline LDL & $2.58(1.07)$ & $3.02(0.99)$ & ns & $2.76(0.85)$ & $3.12(1.07)$ & ns \\
\hline $\mathrm{HDL}$ & $0.79(0.21)$ & $1.0(0.23)$ & 0.003 & $0.97(0.25)$ & $1.08(0.28)$ & 0.010 \\
\hline TG & $2.1(1.61)$ & $2.05(1.16)$ & ns & $1.7(0.86)$ & $1.93(1.21)$ & 0.002 \\
\hline ApoB100 & $0.84(0.36)$ & $0.93(0.36)$ & ns & $0.85(0.26)$ & $0.92(0.36)$ & ns \\
\hline UA & 292 (147) & 355 (88) & ns & 212 (103) & $245(83)$ & 0.004 \\
\hline Glu & $5.19(1.26)$ & $5.27(0.88)$ & ns & $4.97(0.95)$ & $4.86(0.74)$ & ns \\
\hline Waist & $109.5(17)$ & $103(10)$ & 0.003 & 96 (14) & 95 (17) & 0.005 \\
\hline BMI & $31.6(7.41)$ & $29.7(4.16)$ & 0.001 & $30.8(5.83)$ & $29.1(5.62)$ & 0.003 \\
\hline sBP & $136(20)$ & $132(56)$ & ns & $131(27)$ & $130(24)$ & ns \\
\hline $\mathrm{dBP}$ & $85(18)$ & $84(11)$ & ns & $84(15)$ & $83(12)$ & ns \\
\hline hsCRP & 4.7 (3.93) & $1.4(2.09)$ & $<0.001$ & $2.68(5.24)$ & $2.26(6,31)$ & $<0.001$ \\
\hline $\mathrm{BMI}>30$ & $68.1 \%(32)$ & $47.4(18)$ & 0.054 & $54.2 \%(45)$ & $41.5 \%(17)$ & ns \\
\hline $\mathrm{BMI}>25$ & $97.9 \%(46)$ & $97.4 \%(37)$ & ns & $88 \%(73)$ & $82.9(34)$ & ns \\
\hline Smoking & $59.6 \%(28)$ & $31.6 \%$ (12) & 0.010 & $56.8(46)$ & $31.7 \%$ (13) & 0.009 \\
\hline
\end{tabular}


men and women, while LDL cholesterol was insignificant and triglycerides were significantly higher for non-Roma women only. Although selecting the subpopulation with documented metabolic syndrome, we found statistically significant higher waist circumference for the Roma subpopulation as well as higher body mass index. In addition to the classical risk factor smoking, which was significantly higher in the Roma subgroup, we also found statistically significant elevation of hsCRP.

We decided to determine the parameter which has the strongest association with metabolic syndrome. We performed this analysis separately for established criteria of metabolic syndrome and afterwards for uric acid and parameters of lipid spectrum not included in the MS definition, age, apolipoprotein B100, hsCRP, and reported smoking. Gender and ethnic-specific comparisons of the values of these parameters between groups with and without MS are presented in Tables 2-5.

Afterwards, parameters were standardised by computing zscores to allow the comparison of variables with different scales. Due to high intercorrelation between systolic and diastolic blood pressure, we included only systolic blood pressure (SBP) into the model. The same situation occurred with BMI and waist circum- ference, therefore, only waist circumference was included. This analysis was performed separately for Roma men, Roma women, non-Roma men, and non-Roma women (Table 6).

In the subgroup of Roma men, we found that waist circumference conferred the highest chance of MS (one standardised unit increase in waist circumference increased the chance of MS more than 12-times), followed by TG (3.670-times increased risk per one unit increase of TG), SBP (3.505-times increased risk per one unit of increase in SBP) and HDL (3.205-times increased risk per one unit decrease in HDL). Glucose was not found to be a significant and independent predictor of MS in this subgroup of participants.

In the subgroup of Roma women, we found that serum triglycerides conferred the highest chance of MS (one standardised unit increase in TG increased the chance of MS 6.429-times), followed by waist circumference (3.179-times increased risk per one unit increase of waist circumference), SBP (3.078-times increased risk per one unit increase of TG), and HDL (2.451-times increased risk per one unit of decrease in HDL). Glucose conferred the smallest chance of MS per one unit increase (a 1.747-fold higher chance of MS).

Table 2. Gender specific comparisons of individual MS components between participants with and without MS in the Roma subgroup presented as median (IQR)

\begin{tabular}{|l|c|c|c|c|c|c|}
\hline & $\begin{array}{c}\text { Men } \\
\text { MS - }\end{array}$ & $\begin{array}{c}\text { Men } \\
\text { MS }+\end{array}$ & $\mathbf{p}$ & $\begin{array}{c}\text { Women } \\
\text { MS - }\end{array}$ & $\begin{array}{c}\text { Women } \\
\text { MS + }\end{array}$ & p \\
\hline Glu & $4.75(0.59)$ & $5.19(1.26)$ & $<0.001$ & $4.5(0.61)$ & $4.96(0.95)$ & $<0.001$ \\
\hline TG & $0.96(0.59)$ & $2.1(1.61)$ & $<0.001$ & $0.9(0.57)$ & $1.71(1.01)$ & $<0.001$ \\
\hline HDL & $1.07(0.42)$ & $0.79(0.21)$ & $<0.001$ & $1.18(0.34)$ & $0.96(0.25)$ & $<0.001$ \\
\hline Waist & $85(12)$ & $109.5(17)$ & $<0.001$ & $80(16)$ & $96(14)$ & $<0.001$ \\
\hline SBP & $121(17)$ & $136(20)$ & $<0.001$ & $113(14)$ & $131(27)$ & $<0.001$ \\
\hline
\end{tabular}

Table 3. Gender specific comparisons of individual MS components between participants with and without MS in the non-Roma subgroup presented as median (IQR)

\begin{tabular}{|l|c|c|c|c|c|c|}
\hline & $\begin{array}{c}\text { Men } \\
\text { MS - }\end{array}$ & $\begin{array}{c}\text { Men } \\
\text { MS }+\end{array}$ & $\mathbf{p}$ & $\begin{array}{c}\text { Women } \\
\text { MS - }\end{array}$ & $\begin{array}{c}\text { Women } \\
\text { MS + }\end{array}$ & p \\
\hline Glu & $4.83(0.64)$ & $5.27(0.88)$ & 0.002 & $4.69(0.57)$ & $4.87(0.68)$ & $<0.001$ \\
\hline TG & $0.98(0.53)$ & $2.05(1.16)$ & $<0.001$ & $0.85(0.41)$ & $1.89(1.27)$ & $<0.001$ \\
\hline HDL & $1.2(0.35)$ & $1.0(0.23)$ & $<0.001$ & $1.48(0.44)$ & $1.09(0.29)$ & $<0.001$ \\
\hline Waist & $88(11)$ & $103(10)$ & $<0.001$ & $75.8(12)$ & $94(17)$ & $<0.001$ \\
\hline SBP & $122(18)$ & $132(17)$ & $<0.001$ & $115(17)$ & $129(26)$ & $<0.001$ \\
\hline
\end{tabular}

Table 4. Gender specific comparisons of age, Total chol, $L D L$, apoB, hsCRP, uric acid, and smoking between participants with and without MS in the Roma subgroup presented as median (IQR), smoking as a percentage (n)

\begin{tabular}{|l|c|c|c|c|c|c|}
\hline & $\begin{array}{c}\text { Men } \\
\text { MS - }\end{array}$ & $\begin{array}{c}\text { Men } \\
\text { MS + }\end{array}$ & $\mathbf{p}$ & $\begin{array}{c}\text { Women } \\
\text { MS - }\end{array}$ & $\begin{array}{c}\text { Women } \\
\text { MS + }\end{array}$ & p \\
\hline Age & $30.8(14)$ & $40.4(1.59)$ & $<0.001$ & $32.9(13.0)$ & $42.4(10.3)$ & $<0.001$ \\
\hline Cholesterol & $4.47(1.11)$ & $4.9(1.07)$ & 0.037 & $4.6(1.11)$ & $5.15(1.19)$ & $<0.001$ \\
\hline LDL & $2.31(0.87)$ & $2.58(1.07)$ & ns & $2.41(0.86)$ & $2.77(0.9)$ & $<0.001$ \\
\hline ApoBt & $0.69(0.3)$ & $0.84(0.36)$ & 0.001 & $0.71(0.26)$ & $0.88(0.27)$ & $<0.001$ \\
\hline hsCRP & $1.12(2.54)$ & $4.7(3.93)$ & $<0.001$ & $1.03(2.32)$ & $3.02(5.27)$ & $<0.001$ \\
\hline Uric acid & $254(123)$ & $292(147)$ & 0.010 & $191(78)$ & $217(107)$ & 0.003 \\
\hline Smoking & $64 \%(71)$ & $59.6 \%(28)$ & ns & $57.4 \%(113)$ & $56.8 \%(46)$ & $\mathrm{ns}$ \\
\hline
\end{tabular}


Table 5. Gender specific comparisons of age, Total chol, $L D L$, apoB, hsCRP, uric acid, and smoking between participants with and without MS in the non-Roma subgroup presented as median (IQR), smoking as a percentage (n)

\begin{tabular}{|l|c|c|c|c|c|c|}
\hline & $\begin{array}{c}\text { Men } \\
\text { MS - }\end{array}$ & $\begin{array}{c}\text { Men } \\
\text { MS + }\end{array}$ & $\mathbf{p}$ & $\begin{array}{c}\text { Women } \\
\text { MS - }\end{array}$ & $\begin{array}{c}\text { Women } \\
\text { MS + }\end{array}$ & p \\
\hline Age & $32.3(10.4)$ & $36.7(9.48)$ & $<0.001$ & $32.3(10.7)$ & $39(8.19)$ & $<0.001$ \\
\hline Cholesterol & $4.91(1.29)$ & $5.67(1.43)$ & 0.001 & $4.98(1.07)$ & $5.6(1.55)$ & $<0.001$ \\
\hline LDL & $2.63(0.92)$ & $3.01(0.99)$ & 0.004 & $2.43(0.79)$ & $3.11(1.05)$ & $<0.001$ \\
\hline ApoBt & $0.74(0.28)$ & $0.93(0.36)$ & $<0.001$ & $0.67(0.24)$ & $0.91(0.35)$ & $<0.001$ \\
\hline hsCRP & $0.92(1.24)$ & $1.41(2.09)$ & 0.001 & $0.79(1.64)$ & $2.17(6.27)$ & $<0.001$ \\
\hline Uric acid & $294(115)$ & $355(88)$ & $<0.001$ & $212(76)$ & $244(84)$ & 0.001 \\
\hline Smoking & $35.4 \%(51)$ & $31.6 \%(12)$ & $\mathrm{ns}$ & $20.5 \%(34)$ & $31.7 \%(13)$ & $\mathrm{ns}$ \\
\hline
\end{tabular}

Table 6. Results of regression analysis of individual components of MS among four categories of participants

\begin{tabular}{|c|c|c|c|c|c|c|c|c|c|c|c|c|}
\hline & \multicolumn{3}{|c|}{ Roma men } & \multicolumn{3}{|c|}{ Roma women } & \multicolumn{3}{|c|}{ Non-Roma women } & \multicolumn{3}{|c|}{ Non-Roma men } \\
\hline & $\mathrm{p}$ & OR & $95 \% \mathrm{Cl}$ & $p$ & OR & $95 \% \mathrm{Cl}$ & $p$ & OR & $95 \% \mathrm{Cl}$ & $p$ & OR & $95 \% \mathrm{Cl}$ \\
\hline TAG & 0.023 & 3.670 & $1.195-11.271$ & 0.021 & 1.767 & $1.090-2.863$ & 0.361 & 1.834 & $0.499-6.743$ & 0.012 & 3.976 & $1.363-11.601$ \\
\hline $\mathrm{HDL}$ & 0.036 & 0.312 & $0.105-0.929$ & $<0.001$ & 6.429 & $2.823-14.638$ & $<0.001$ & 21.552 & $5.116-90.796$ & 0.277 & 1.441 & $0.746-2.783$ \\
\hline Glu & 0.383 & 1.590 & $0.561-4.503$ & 0.025 & 0.408 & $0.187-0.892$ & 0.007 & 0.263 & $0.100-0.692$ & 0.010 & 0.230 & $0.075-0.707$ \\
\hline SBP & 0.009 & 3.505 & $1.364-9.007$ & $<0.001$ & 3.179 & $1.752-5.770$ & 0.008 & 3.391 & $1.374-8.364$ & $<0.001$ & 16.172 & $4.940-52.944$ \\
\hline Waist & $<0.001$ & 12.128 & $3.660-40.187$ & $<0.001$ & 5.698 & $3.078-10.548$ & $<0.001$ & 4.363 & $2.057-9.255$ & 0.028 & 2.209 & $1.087-4.487$ \\
\hline Constant & $<0.001$ & 0.106 & & $<0.001$ & 0.240 & & 0.002 & 0.347 & & $<0.001$ & 0.013 & \\
\hline
\end{tabular}

In the subgroup of non-Roma women, we found that serum triglycerides conferred the highest chance of MS (one standardised unit increase in TG increased the chance of MS more than 21-times), followed by SBP (4.363-times increased risk per one unit increase of SBP), HDL (3.802-times increased risk per one unit of decrease in HDL), and waist circumference (3.391-times increased risk per one unit increase of waist circumference). Glucose was not found to be a significant and independent predictor of MS in this subgroup of participants.

In the subgroup of non-Roma men, we found that waist circumference conferred the highest chance of MS (one standardised unit increase in waist circumference increased the chance of MS more than 16-times), followed by HDL (4.348-times increased risk per one unit decrease in HDL), glucose (3.976-times increased risk per one unit increase of glucose), and SBP (2.209-times increased risk per one unit of increase in SBP). TGs were not found to be a significant and independent predictor of MS in this subgroup of participants.

Comparing non-classical risk factors for MS we found that only age (with OR 1.977) and hsCRP (OR 1.887) were significant and independent predictors of MS in Roma men. Among Roma women apolipoprotein B100 was also found to be an independent predictor of MS, besides age and hsCRP. Furthermore, in this subgroup apoB100 conferred the highest chance of MS (2.864-fold increase per one standardised unit increase in apoB100). Among nonRoma women apolipoprotein B100 was found to be the strongest independent predictor of MS (OR 5.884) besides age. HsCRP was not found to be an independent predictor of MS in this subgroup. Among non-Roma men uric acid was found to be the strongest independent predictor of MS (OR 2.696) followed by apolipoprotein B100 (OR 2.44) and age (OR 2.141). HsCRP was not found to be an independent predictor of MS in this subgroup (Table 7).

\section{DISCUSSION}

Statistically significant higher waist circumference for the Roma subpopulation as well as higher body mass index was found in the study group (although selected population with metabolic syndrome). HDL cholesterol was significantly lower for both Roma men and women as reported before, but in contrast, LDL cholesterol was insignificant for men and women with metabolic syndrome (16).

Data from this study shows that along with age - a significant predictor in each subgroup - waist circumference was the most important risk factor increasing the chances for developing metabolic syndrome in Roma men and non-Roma men. Among Roma and non-Roma women triacylglyceroles played the most important role for developing MS. For instance, it has been shown that patients with abdominal obesity and low HDL-cholesterol concentrations are frequently characterised by a triad of metabolic abnormalities, the so-called atherogenic metabolic triad, even in the absence of type 2 diabetes. In addition, these patients have a high triglycerides and low HDL-cholesterol dyslipidemic state, despite the fact that they are not necessarily characterised by elevated LDL-cholesterol. This situation is misleading from a risk-assessment standpoint, since these patients have usually an increased concentration of small, dense LDL particles (17). This finding could also be applied to the population without a previous history of CVD or diabetes. Després and his team at Laval University in Québec City, interested in developing a simple screening approach, have proposed that a hypertriglyceridemic waist could represent a simple high-risk obesity phenotype to identify individuals likely to have the features of metabolic syndrome. The rationale behind this approach is very simple: waist circumference has been shown to be a good correlate to the 
Table 7. Results of regression analysis of standardised values of age, Total chol, LDL, apoB, hsCRP, uric acid, and smoking with MS as dependent variable among Roma men

\begin{tabular}{|l|c|c|c|c|c|c|c|c|c|c|c|c|}
\hline & \multicolumn{3}{|c|}{ Roma men } & \multicolumn{4}{c|}{ Roma women } & \multicolumn{3}{c|}{ Non-Roma women } & \multicolumn{3}{c|}{ Non-Roma men } \\
\cline { 2 - 14 } & $\mathrm{p}$ & OR & $95 \% \mathrm{Cl}$ & $\mathrm{p}$ & OR & $95 \% \mathrm{Cl}$ & $\mathrm{p}$ & OR & $95 \% \mathrm{Cl}$ & $\mathrm{p}$ & OR & $95 \% \mathrm{Cl}$ \\
\hline Age & 0.004 & 1.977 & $1.240-3.151$ & $<0.001$ & 2.668 & $1.863-3.820$ & $<0.001$ & 2.746 & $1.566-4.814$ & 0.004 & 2.141 & $1.276-3.592$ \\
\hline Cholesterol & 0.191 & 1.752 & $0.756-4.062$ & 0.563 & 0.729 & $0.249-2.130$ & 0.260 & 0.449 & $0.111-1.811$ & 0.745 & 0.823 & $0.255-2.655$ \\
\hline $\begin{array}{l}\text { LDL } \\
\text { cholesterol }\end{array}$ & 0.055 & 0.358 & $0.125-1.021$ & 0.564 & 0.727 & $0.246-2.148$ & 0.876 & 0.887 & $0.197-3.990$ & 0.709 & 0.801 & $0.250-2.568$ \\
\hline ApoB1 & 0.101 & 2.231 & $0.855-5.822$ & 0.005 & 2.864 & $1.379-5.948$ & $<0.001$ & 5.884 & $2.244-15.429$ & 0.002 & 2.440 & $1.398-4.260$ \\
\hline hcCRP & 0.004 & 1.887 & $1.220-2.917$ & 0.001 & 1.808 & $1.291-2.531$ & 0.374 & 1.230 & $0.780-1.940$ & 0.480 & 1.240 & $0.683-2.251$ \\
\hline Uric acid & 0.512 & 1.150 & $0.758-1.745$ & 0.073 & 1.501 & $0.963-2.340$ & 0.054 & 1.844 & $0.990-3.434$ & $<0.001$ & 2.696 & $1.640-4.434$ \\
\hline Smoking & 0.234 & 1.683 & $0.714-3.972$ & 0.900 & 0.979 & $0.699-1.370$ & 0.080 & 0.399 & $0.143-1.116$ & 0.878 & 1.072 & $0.442-2.603$ \\
\hline Constant & $<0.001$ & 0.282 & & $<0.001$ & 0.279 & & 0.073 & 0.446 & & $<0.001$ & 0.078 & \\
\hline
\end{tabular}

amount of visceral fat. On the basis of the relationship between visceral adipose tissue accumulation and waist circumference, good relationships were found between waist circumference and fasting insulin and apolipoprotein B concentrations. Many groups around the world have also reported that in order to predict LDL particle size, fasting triglyceride concentration is by far the best variable of the simple lipid profile that most family doctors can obtain from the clinical biochemistry laboratory (18). In our study, we described apolipoprotein B concentrations as being associated with a higher chance for developing MS.

In Roma men glucose did not play a role at all, and in nonRoma men triglycerides did not play a role. Plasma glucose in non-Roma women did not play a role and in Roma women it was the weakest risk factor. We did not confirm hyperglyceamia among the Roma population published in the previous study (19), which could be explained by younger population selected for this study since hyperglycemia is the tip of a huge atherogenic, thrombotic and inflammatory iceberg, which substantially increases the risk of $\mathrm{CV}$ diseases due to missing prevention in Roma settlements.

We found uric acid as a strong predictor in non-Roma men. This finding could confirm the potential causal role of uric acid in metabolic syndrome, where elevated uric acid is common in subjects with insulin resistance and obesity. Some studies suggest that uric acid may simply be a consequence of the presence of oxidative stress or hyperinsulinemia present in subjects with metabolic syndrome, and there is increasing evidence that uric acid could have a contributory causal role. Firstly, elevated serum uric acid often precedes the development of obesity and metabolic syndrome. Secondly, experimental and clinical studies provide increasing evidence that excessive intake of fructose, primarily in the form of added sugars, may have a key role in the development of metabolic syndrome (20). Serum uric acid was an independent risk factor for incident diabetes, and evidence shows that patients with both gout and type 2 diabetes exhibited a mutual inter-dependent effect on higher incidences. Furthermore, obese patients often demonstrated insulin resistance and adipose tissue macrophages with low-grade inflammation, which is suggested as being a major contributor for increased risk of cardiovascular diseases (21).

HsCRP alone was not a good predictor of MS for non-Roma, but was associated with MS among the Roma population. Lemieux et al. examined the relationship between hsCRP and visceral adipose tissue accumulation and reported that hsCRP concentration was significantly associated with the amount of visceral fat. Thus, they found that viscerally obese patients were characterised by the highest hsCRP concentrations. Moreover, they also reported that a very simple marker of abdominal adiposity, waist circumference, was the best predictor of an elevated hsCRP concentration in a sample of 159 men (22).

\section{CONCLUSION}

Our study confirmed that the prevalence of metabolic syndrome is strongly associated with the hypertriglyceridemic waist, besides other risk factors, a marker of the atherogenic metabolic triad among younger Roma population, which may be the reason for the increased CV morbidity and mortality in elderly Roma compared with non-Roma. In light of these results, better prevention of CV events for Roma minority settlements in Slovakia should be provided.

\section{Acknowledgement}

This work was partially supported by the Agency of the Slovak Ministry of Education for the Structural Funds of EU CEMIO-ITMS: 26220120058 (30\%) and DIAGONKO-ITMS: 26220220153 (30\%), the project VEGA grant 1/1072/12, a grant of Visegrad fund, and by Roche Slovensko, s. r. o. This paper was also partially funded within the framework of the project "Social determinants of health in socially and physically disadvantaged and other groups of population” (CZ.1.07/2.3.00/20.0063).

\section{Conflict of Interests}

None declared

\section{APPENDIX}

HepaMeta Team: Peter Jarčuška, Andrea Madarasová Gecková, Mária Mareková, Daniel Pella, Leonard Siegfried, Pavol Jarčuška, Lýdia Pastvová, Ján Fedačko, Jana Kollárová, Peter Kolarčik, Daniela Bobáková, Zuzana Veselská, Ingrid Babinská, Sylvia Dražilová, Jaroslav Rosenberger, Ivan Schréter, Pavol Kristian, Eduard Veselíny, Martin Janičko, Ladislav Virág, Anna Birková, 
Marta Kmet’ová, Monika Halánová, Darina Petrášová, Katarína Cáriková, Viera Lovayová, Lucia Merkovská, Lucia Jedličková, Ivana Valková

\section{REFERENCES}

1. Kannel WB, Cupples LA, Ramaswami R, Stokes J 3rd, Kreger BE, Higgins M. Regional obesity and risk of cardiovascular disease; the Framingham Study. J Clin Epidemiol. 1991;44(2):183-90.

2. Isomaa B, Almgren P, Tuomi T, Forsén B, Lahti K, Nissén M, et al. Cardiovascular morbidity and mortality associated with the metabolic syndrome. Diabetes Care. 2001 Apr;24(4):683-9.

3. Alexander CM, Landsman PB, Teutsch SM, Haffner SM; Third National Health and Nutrition Examination Survey (NHANES III); National Cholesterol Education Program (NCEP). NCEP-defined metabolic syndrome, diabetes, and prevalence of coronary heart disease among NHANES III participants age 50 years and older. Diabetes. 2003 May;52(5):1210-4.

4. Hunt KJ, Resendez RG, Williams K, Haffner SM, Stern MP; San Antonio Heart Study. National Cholesterol Education Program versus World Health Organization metabolic syndrome in relation to all-cause and cardiovascular mortality in the San Antonio Heart Study. Circulation. 2004 Sep 7;110(10):1251-7.

5. Lakka HM, Laaksonen DE, Lakka TA, Niskanen LK, Kumpusalo E, Tuomilehto J, et al. The metabolic syndrome and total and cardiovascular disease mortality in middle-aged men. JAMA. 2002 Dec 4;288(21):270916.

6. Grundy SM, Hansen B, Smith SC Jr, Cleeman JI, Kahn RA; American Heart Association; National Heart, Lung, and Blood Institute; American Diabetes Association. Clinical management of metabolic syndrome: report of the American Heart Association/National Heart, Lung, and Blood Institute/American Diabetes Association conference on scientific issues related to management. Circulation. 2004 Feb 3;109(4):551-6.

7. National Cholesterol Education Program (NCEP) Expert Panel on Detection, Evaluation, and Treatment of High Blood Cholesterol in Adults (Adult Treatment Panel III). Third Report of the National Cholesterol Education Program (NCEP) Expert Panel on Detection, Evaluation, and Treatment of High Blood Cholesterol in Adults (Adult Treatment Panel III) final report. Circulation. 2002 Dec 17;106(25):3143-421.

8. Baker D, Mead N, Campbell S. Inequalities in morbidity and consulting behaviour for socially vulnerable groups. Br J Gen Pract. 2002 Feb;52(475):124-30.

9. Cappuccio FP. Ethnicity and cardiovascular risk: variations in people of African ancestry and South Asian origin. J Hum Hypertens. 1997 Sep;11(9):571-6.
10. Krcho P, Bazárová J, Diheneščíková D. Composition of the mother milk during the first five days in low and high risk population. Acta Med Port. 2012;25 Suppl 2:163.

11. Ginter E, Krajcovicova-Kudlackova M, Kacala O, Kovacic V, Valachovicova M. Health status of Romanies (Gypsies) in the Slovak Republic and in the neighbouring countries. Bratisl Lek Listy. 2001;102(10):479-84.

12. Dolinska S, Kudlackova M, Ginter E. The prevalence of female obesity in the world and in the Slovak Gypsy women. Bratisl Lek Listy. 2007;108(45):207-11.

13. Sinha S, Misra P, Kant S, Krishnan A, Nongkynrih B, Vikram NK. Prevalence of metabolic syndrome and its selected determinants among urban adult women in South Delhi, India. Postgrad Med J. 2013 Feb;89(1048):68-72.

14. Koupilová I, Epstein H, Holčík J, Hajioff S, McKee M. Health needs of the Roma population in the Czech and Slovak Republics. Soc Sci Med. 2001 Nov;53(9):1191-204.

15. Madarasová Gecková A, Jarčuška P, Mareková M, Pella D, Siegfried L, Jarčuška P, et al.; HepaMeta Team. HepaMeta - Prevalence of hepatitis $\mathrm{B} / \mathrm{C}$ and metabolic syndrome in population living in separated and segregated Roma settlements: a methodology for a cross-sectional populationbased study using community-based approach. Cent Eur J Public Health. 2014 Mar;22 Suppl:S6-11.

16. Vozarova de Courten B, de Courten M, Hanson RL, Zahorakova A, Egyenes HP, Tataranni PA, et al. Higher prevalence of type 2 diabetes, metabolic syndrome and cardiovascular diseases in gypsies than in nongypsies in Slovakia. Diabetes Res Clin Pract. 2003 Nov;62(2):95-103.

17. Lemieux I, Pascot A, Almeras, N. Obesity in the 21(st) century: new approaches? Ann Endocrinol (Paris). 2001;62(4):255-61.

18. Després JP, Lemieux I, Prud'homme D. Treatment of obesity: need to focus on high risk abdominally obese patients. BMJ. 2001 Mar 24;322(7288):716-20.

19. Ostrihoňová T, Bérešová J. Occurrence of metabolic syndrome and its risk factors amongst a selected group of Roma inhabitants. Hygiena 2010;55(1):7-14. (In Slovak.)

20. Lanaspa MA, Sautin YY, Ejaz AA, Madero M, Le MP, Manitius J, et al. Uric acid and metabolic syndrome: what is the relationship? Curr Rheumatol Rev. 2011;7(2):162-9.

21. Li C, Hsieh MC, Chang SJ. Metabolic syndrome, diabetes, and hyperuricemia. Curr Opin Rheumatol. 2013 Mar;25(2):210-6.

22. Lemieux I, Pascot A, Prud'homme D, Alméras N, Bogaty P, Nadeau A, et al. Elevated C-reactive protein: another component of the atherothrombotic profile of abdominal obesity. Arterioscler Thromb Vasc Biol. 2001 Jun;21(6):961-7. 